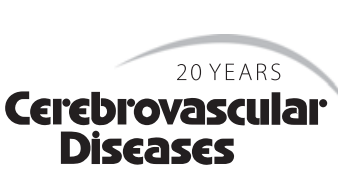

Diseases

\title{
Navigating the Gray Zones of Stroke Management for a Graying Population
}

\author{
Meng Lee ${ }^{a, b} \quad$ Bruce Ovbiagele ${ }^{a}$ \\ aStroke Center and Department of Neurology, UCLA Medical Center, Los Angeles, Calif., USA; \\ ${ }^{b}$ Department of Neurology, Chang Gung Memorial Hospital and University College of Medicine, \\ Chiayi, Taiwan, ROC
}

The world is rapidly graying [1]. This global shift in age structure towards very elderly populations ( $\geq 80$ years) is primarily due to improvements in living standards and healthcare resulting in greater disease-free and diseasespecific survival [1]. Since stroke occurrence is most pronounced in the elderly population, there are increasingly higher numbers of these individuals presenting to hospitals for acute stroke treatment, as well as rising prevalence rates of elderly stroke survivors living with stroke-related disability [1]. Furthermore, even with better life expectancy and greater rates of stroke survival, the likelihood of dying tends to rise with increasing age after an index stroke [2], and so these evolving demographic patterns have led to projections that stroke will be the leading cause of death in developed nations within 30 years [3]. In light of the immense burden associated with stroke among the elderly, it is not surprising that the financial costs attributable to stroke in the elderly are extremely high, with most of the total expenditure for stroke being in persons aged $\geq 65$ years [4]. To meet these burgeoning challenges, healthcare providers, research funding agencies and policy makerswill increasingly need to explore avenues for providing systematic evidence-based stroke care that optimizes favorable outcomes for the very elderly [1].

Fortunately, the ravages of stroke are not inevitable or untreatable. Greater emphasis on early recognition, pa- tient awareness and effective timely treatment may mitigate its effects among the very elderly [1]. However, recent practice findings suggest that elderly patients generally receive lower quality stroke care than their younger counterparts, and these care disparities encompass various aspects of stroke management including acute care and secondary prevention $[5,6]$. There should be no reason to deny any stroke therapy based on age alone, but it is conceivable that the multidimensional health status of much older adults presents challenges that may influence appropriate stroke management, leading to stroke therapeutic inertia by physicians caring for these patients. These challenges may include concerns about multiple comorbidities, drug interactions, cost-effectiveness and a paucity of evidence-based stroke studies in very elderly populations. For instance, it has been shown that cognitive impairment and disability are strong independent correlates of lack of secondary stroke prevention treatment in older patients [7]. Such challenges notwithstanding, accruing data indicate that several therapies used in younger middle-aged stroke patients can be administered to very elderly patients with generally similar efficacy and acceptable side effect profiles [1]. In fact, there is evidence that elderly stroke patients achieve improved clinical outcomes when provided with optimal care [8].

Currently, stroke therapies in the very elderly can be roughly divided into 3 categories on available evidence

\section{KARGER}

(c) 2010 S. Karger AG, Basel

Fax +41613061234 E-Mail karger@karger.ch www.karger.com
Accessible online at: www.karger.com/ced
Bruce Ovbiagele, MD, MSc

Stroke Center and Department of Neurology, University of California at Los Angeles 710 Westwood Plaza

Los Angeles, CA 90095 (USA)

Tel. +1 310794 6379, Fax +1 310267 2063,E-Mail Ovibes@ mednet.ucla.edu 


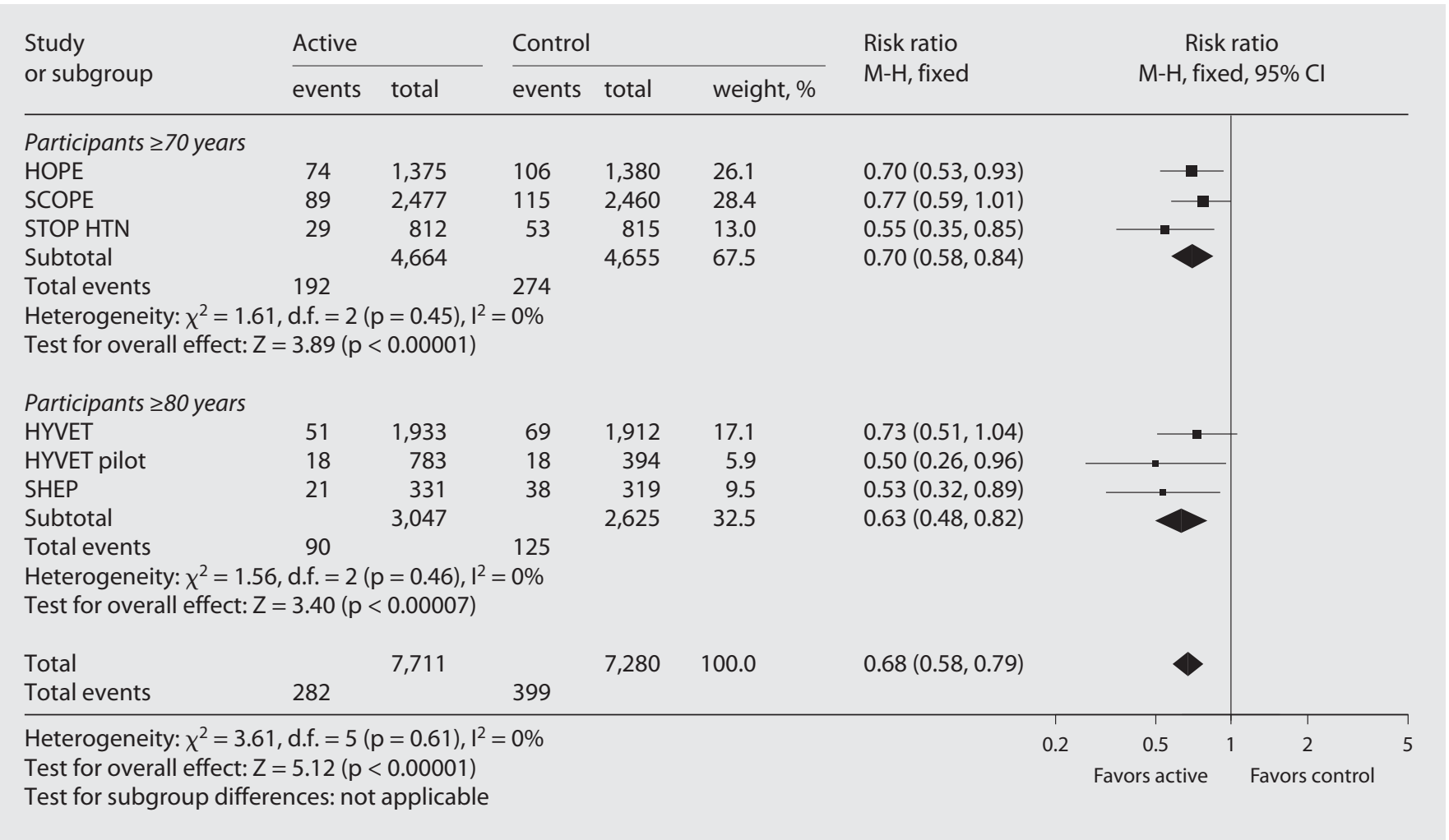

Fig. 1. Meta-analysis of randomized controlled trials with stroke endpoints for antihypertensive treatment vs. placebo in clinical trial participants $\geq 70$ years and $\geq 80$ years. Figures in parentheses are $95 \%$ confidence limits. HOPE = Heart Outcomes Prevention Evaluation; SCOPE = Study on Cognition and Prognosis in the Elderly; STOP HTN = Swedish Trial in Old Patients with Hypertension; SHEP = Systolic Hypertension in the Elderly Program.

and practitioner concerns. Enhancing stroke outcomes in the very elderly will require various strategies geared at mitigating issues within each category.

(1) Treatments with multiple studies showing strong efficacy but with poor translation into routine clinical practice largely due to practitioners' overly heightened concerns about safety in this age group (e.g. stroke prevention using anticoagulation in patients with atrial fibrillation).

(2) Treatments with $<2$ clinical trials showing efficacy or clinical trials with less intensive biomarker targets, making some clinicians wary of implementing the therapies until additional independent confirmation via other trials has occurred or there is evidence replicating the benefits of aggressive biomarker treatment seen in younger patients (e.g. primary vascular risk reduction with antihypertensives or statins).

(3) Treatments that do not have specific proven clinical efficacy in the very elderly but based on post hoc trial analyses and observational studies appear to carry a favorable risk-benefit ratio (e.g. thrombolysis for acute ischemic stroke, secondary stroke prevention with antihypertensives/statins/antiplatelet drugs, revascularization procedures, stroke units), prompting questions about whether the benefits of treatment seen in younger patients can be safely and effectively extended to the very elderly [9].

Although the incidence of atrial fibrillation rises with age, many otherwise eligible elderly patients do not receive anticoagulation therapy because of fear of complications [1]. Compelling clinical trial data indicate that anticoagulation of very elderly persons with atrial fibrillation is safe and efficacious [1], with 1 study showing that targeted anticoagulation with warfarin was associated with $>50 \%$ relative risk reduction (RRR) of ischemic and hemorrhagic events with similar rates of extracranial hemorrhage when compared with aspirin [10]. Improving the appropriate use of warfarin in elderly persons 


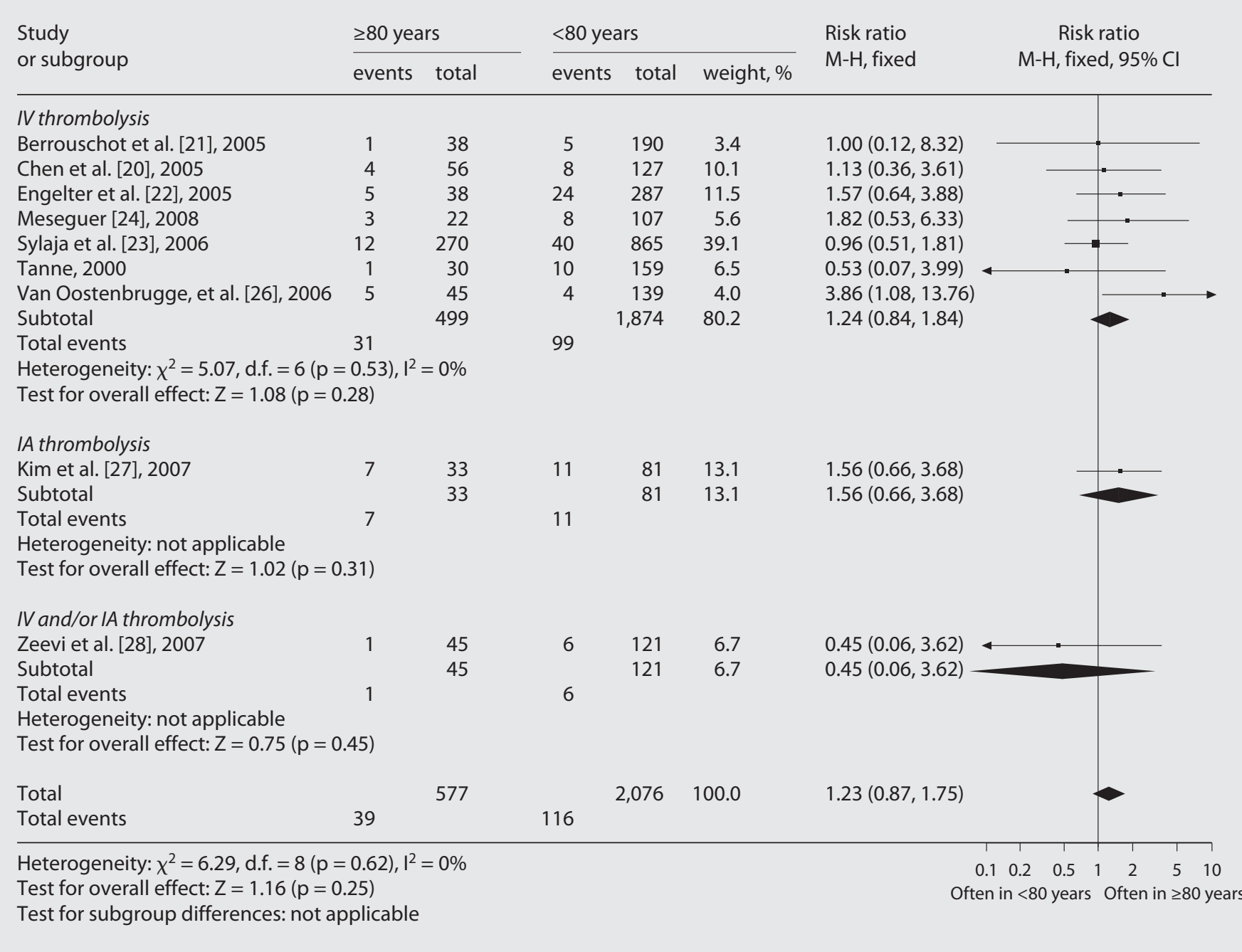

Fig. 2. Meta-analysis of observational studies comparing subjects aged $\geq 80$ years vs. $<80$ years for the endpoint of symptomatic ICH after thrombolytic therapy for acute ischemic stroke. Figures in parentheses are $95 \%$ confidence limits.

with atrial fibrillation will require better practitioner education and wider dissemination of practice guidelines. Fortunately, less tedious and safer agents than warfarin appear to be on the horizon [11], and other regimens superior to aspirin alone are now available for patients who are clearly not eligible for warfarin [1]. These recent advancements could go a long way in promoting favorable stroke outcomes in the very elderly with atrial fibrillation.

Treatment of hypertension in the very elderly is an exemplar of the second category listed above. Despite the role of elevated blood pressure as a strong modifiable vascular risk factor, the very elderly are less likely to have their blood pressure under control [12]. Recently, the Hypertension in the Very Elderly Trial (HYVET), the only trial so far to have specifically explored antihypertensive therapy in persons aged $\geq 80$ years, showed that antihypertensive treatment was associated with a $30 \%$ RRR in stroke and a $21 \%$ RRR in mortality [13]. To further explore the consistency of this effect, we conducted a metaanalysis of antihypertensive clinical trials [13-18], which reported stroke events in individuals aged $\geq 70$ years (fig. 1). Based on these pooled data, it is clear that antihypertensive treatment is robustly efficacious in lowering the stroke risk among elderly persons including those $\geq 80$ years. An unresolved major issue is whether more 
intensive goals than the systolic blood pressure target of $<150 \mathrm{~mm} \mathrm{Hg}$ in HYVET would be associated with further reductions in risk as seen in younger patients or result in decreased tolerability, cognitive decline and compliance [1].

Thrombolysis for acute ischemic stroke falls in the last category. Although most observational data suggest a benefit from thrombolysis for the very elderly, 1 metaanalysis of stroke patients aged $\geq 80$ years treated with intravenous thrombolysis showed a less favorable outcome at 3 months compared to younger patients [19]. This age-outcome difference is probably best explained by the higher burden of established factors associated with poor stroke prognosis among the very elderly versus their younger counterparts. Still, the dreaded complication of treatment that tends to limit the administration of thrombolytics in the very elderly is intracranial hemorrhage (ICH). To this end, we performed an updated meta-analysis [20-28] and noted that being very elderly did not significantly increase the risk of symptomatic ICH after thrombolytic therapy (fig. 2). Thus, it would appear that concerns about symptomatic ICH should not necessarily preclude the use of thrombolysis in very elderly acute ischemic stroke patients on the basis of age alone. Specific clinical trials would best resolve this issue.

In conclusion, despite the rapid growth in the very elderly population, who are especially stroke prone, these individuals are much less likely than their younger counterparts to receive evidence-based treatment for reduction of risk factors or acute stroke treatment in the 'real world' [1]. Although specific evidence for several stroke therapies in the oldest subset of the population is urgently needed, these patients seem to be potential candidates for the full range of strategies recommended for younger patients [1]. Indeed, the best available evidence indicates that some of these therapies can be safely and effectively used in very elderly patients with or at risk of stroke. Going forward, there is a tremendous opportunity to pro- mote successful aging and boost functional life years via concerted efforts targeting the very elderly with stroke.

In our view, addressing these challenges will necessitate the following.

(1) Issuance of specific guidelines for practitioners caring for the very elderly with or at risk of stroke, as has been done for the very elderly with coronary artery disease. [29]. These guidelines could also include concise yet practical summaries of potential risks and benefits so that clinicians can readily incorporate this information into informative discussions with patients and caregivers.

(2) Greater integration of key care components (primary care, neurologists, nursing, social services, telemedicine, rehabilitation and pharmacists), including quality improvement initiatives that incorporate systematic evidence-based care that may improve stroke treatment processes and therefore outcomes [30]. Furthermore, support from policy makers at all levels will be needed to modify the current approach to stroke treatment among the very elderly so that equitable and effective therapies can be optimally provided within our increasingly aging society [31].

(3) Stroke clinical trials specifically aimed at the very elderly. Doing so would greatly convince skeptical clinicians and the general population that all patients with stroke could benefit from prompt evidence-based treatment, regardless of age. Such research may also provide novel insights into stroke outcomes in the oldest old and should include pivotal endpoints encompassing quality of life and not just survival alone [31].

\section{Acknowledgements}

B.O. received support from the University of California, Los Angeles, Resource Centers for Minority Aging Research Center for Health Improvement of Minority Elderly under NIH/NIA grant P30-AG021684.

\section{References}

Sanossian N, Ovbiagele B: Prevention and management of stroke in very elderly patients. Lancet Neurol 2009;8:1031-1041.

-2 Saposnik G, Cote R, Phillips S, et al: Stroke outcome in those over 80: a multicenter cohort study across Canada. Stroke 2008;39: 2310-2317.

3 Marini C, Baldassarre M, Russo T, et al: Burden of first-ever ischemic stroke in the oldest old: evidence from a population-based study. Neurology 2004;62:77-81.
4 Hodgson TA, Cohen AJ: Medical care expenditures for selected circulatory diseases: opportunities for reducing national health expenditures. Med Care 1999;37:994-1012.

5 Kaplan RC, Tirschwell DL, Longstreth WT Jr, et al: Vascular events, mortality, and preventive therapy following ischemic stroke in the elderly. Neurology 2005;65:835-842. 
6 Palnum KD, Petersen P, Sorensen HT, et al: Older patients with acute stroke in Denmark: quality of care and short-term mortality - a nationwide follow-up study. Age Ageing 2008;37:90-95.

$\checkmark 7$ Moroney JT, Tseng CL, Paik MC, Mohr JP, Desmond DW: Treatment for the secondary prevention of stroke in older patients: the influence of dementia status. J Am Geriatr Soc 1999;47:824-829.

8 Stroke Unit Trialists' Collaboration: Organised inpatient (stroke unit) care for stroke. Cochrane Database Syst Rev 2007; 4:CD000197. DOI: 000110.001002/14651858. CD14000197.pub14651852.

-9 Bushnell CD, Colon-Emeric CS: Secondary stroke prevention strategies for the oldest patients: possibilities and challenges. Drugs Aging 2009;26:209-230.

10 Mant J, Hobbs FD, Fletcher K, et al: Warfarin versus aspirin for stroke prevention in an elderly community population with atrial fibrillation (the Birmingham Atrial Fibrillation Treatment of the Aged Study, BAFTA): a randomised controlled trial. Lancet 2007; 370:493-503.

-11 Connolly SJ, Ezekowitz MD, Yusuf S, et al: Dabigatran versus warfarin in patients with atrial fibrillation. N Engl J Med 2009;361: 1139-1151.

-12 Weycker D, Edelsberg J, Vincze G, Levy DG, Kartashov A, Oster G: Blood pressure control in patients initiating antihypertensive therapy. Ann Pharmacother 2008;42:169176.

$\checkmark 13$ Beckett NS, Peters R, Fletcher AE, et al: Treatment of hypertension in patients 80 years of age or older. N Engl J Med 2008;358: 1887-1898.

14 Systolic Hypertension in the Elderly Program Cooperative Research Group: Implications of the systolic hypertension in the elderly program. Hypertension 1993;21:335343.
15 Staessen JA, Fagard R, Thijs L, et al: Subgroup and per-protocol analysis of the randomized European Trial on Isolated Systolic Hypertension in the Elderly. Arch Intern Med 1998;158:1681-1691.

16 Dahlof B, Lindholm LH, Hansson L, Schersten B, Ekbom T, Wester PO: Morbidity and mortality in the Swedish Trial in Old Patients with Hypertension (STOP-Hypertension). Lancet 1991;338:1281-1285.

17 Lithell H, Hansson L, Skoog I, et al: The Study on Cognition and Prognosis in the Elderly (SCOPE): principal results of a randomized double-blind intervention trial. J Hypertens 2003;21:875-886.

18 Gianni M, Bosch J, Pogue J, et al: Effect of long-term ACE-inhibitor therapy in elderly vascular disease patients. Eur Heart J 2007; 28:1382-1388

19 Engelter ST, Bonati LH, Lyrer PA: Intravenous thrombolysis in stroke patients of $\geq 80$ versus $<80$ years of age - a systematic review across cohort studies. Age Ageing 2006;35: 572-580.

20 Chen CI, Iguchi Y, Grotta JC, et al: Intravenous TPA for very old stroke patients. Eur Neurol 2005;54:140-144.

21 Berrouschot J, Rother J, Glahn J, Kucinski T, Fiehler J, Thomalla G: Outcome and severe hemorrhagic complications of intravenous thrombolysis with tissue plasminogen activator in very old ( $\geq 80$ years) stroke patients. Stroke 2005;36:2421-2425.

22 Engelter ST, Reichhart M, Sekoranja L, Georgiadis D, Baumann A, Weder B, Müller F, Lüthy R, Arnold M, Michel P, Mattle HP, Tettenborn B, Hungerbühler HJ, Baumgartner RW, Sztajzel R, Bogousslavsky J, Lyrer PA: Thrombolysis in stroke patients aged 80 years and older: Swiss survey of IV thrombolysis. Neurology 2005;65:1795-1798.
23 Sylaja PN, Cote R, Buchan AM, Hill MD: Thrombolysis in patients older than 80 years with acute ischaemic stroke: Canadian Alteplase for Stroke Effectiveness Study. J Neurol Neurosurg Psychiatry 2006;77:826-829.

24 Meseguer E, Labreuche J, Olivot JM, et al: Determinants of outcome and safety of intravenous rt-PA therapy in the very old: a clinical registry study and systematic review. Age Ageing 2008;37:107-111.

25 Tanne D, Gorman MJ, Bates VE, et al: Intravenous tissue plasminogen activator for acute ischemic stroke in patients aged 80 years and older: the tPA stroke survey experience. Stroke 2000;31:370-375.

26 Van Oostenbrugge RJ, Hupperts RM, Lodder J: Thrombolysis for acute stroke with special emphasis on the very old: experience from a single Dutch centre. J Neurol Neurosurg Psychiatry 2006;77:375-377.

27 Kim D, Ford GA, Kidwell CS, et al: Intra-arterial thrombolysis for acute stroke in patients 80 and older: a comparison of results in patients younger than 80 years. AJNR Am J Neuroradiol 2007;28:159-163.

$>28$ Zeevi N, Chhabra J, Silverman IE, Lee NS, McCullough LD: Acute stroke management in the elderly. Cerebrovasc Dis 2007;23:304308 .

29 Williams MA, Fleg JL, Ades PA, et al: Secondary prevention of coronary heart disease in the elderly (with emphasis on patients $\geq 75$ years of age): an American Heart Association scientific statement from the Council on Clinical Cardiology Subcommittee on Exercise, Cardiac Rehabilitation, and Prevention. Circulation 2002;105:1735-1743.

30 Ovbiagele B: Pessin award lecture 2008: lessons from the Stroke PROTECT program. J Neurol Sci 2008;275:1-6.

-31 Kriekard P, Gharacholou SM, Peterson ED: Primary and secondary prevention of cardiovascular disease in older adults: a status report. Clin Geriatr Med 2009;25:745-755, x. 